\title{
SUSTAINED PEAK LOW-CYCLE FATIGUE IN SINGLE CRYSTALS WITH EQUILIBRIUM $\gamma-\gamma^{\prime}$ COATINGS
}

\author{
M. A. Lafata ${ }^{1}$, L. H. Rettberg ${ }^{1}$, C. Mercer $^{2}$, T. M. Pollock ${ }^{1}$ \\ ${ }^{1}$ Materials Department, University of California Santa Barbara; Santa Barbara, CA, 93106-5050, USA \\ ${ }^{2}$ National Institute for Materials Science; 1-2-1 Sengen, Tsukuba, Ibaraki, 305-0047, Japan
}

Keywords: Bond Coat, René N5, TMS-138A, Low-Cycle Fatigue

\begin{abstract}
Damage due to fatigue with compressive holds developed during cycling of two single crystal superalloys, René N5 and TMS-138A, with equilibrium (EQ) $\gamma-\gamma^{\prime}$ bond coatings has been examined. Isothermal strain-controlled fatigue tests with a two minute compressive hold were performed at $1093{ }^{\circ} \mathrm{C}$ with a total strain range of $0.35 \%$. Oxide-assisted fatigue cracks initiate at the bond coat surface before penetrating into the single crystal superalloy. Crack depths and spacing were characterized in interrupted and failed specimens to investigate crack initiation and propagation behavior. The EQ coatings were found to enhance crack penetration rates compared to previous studies on uncoated superalloys and $\beta$-based bond coats. Electron backscatter diffraction and energy dispersive spectroscopy were used to characterize the microstructure of the EQ coating and oxides on the cracks. The EQ coating was found to have a coarse two-phase structure and a small (3-4 $\mu \mathrm{m}$ ) grain size. The implications of coating microstructure, strength, and thickness are discussed with regard to fatigue lifetime.
\end{abstract}

\section{Introduction}

Continued increases in gas-turbine operating temperature and a corresponding reduction in fuel consumption require improvements in the materials system used for turbine blades. Two important developments have been cast thin-walled airfoils with complex internal cooling passages, and the use of multilayered coating systems to thermally insulate the blade from hot combustion gases [1]. Typical thermal barrier coating systems consist of a single crystal nickel base superalloy substrate, a bond coat, a thermally grown oxide (TGO), and a ceramic yttria-stabilized zirconia (YSZ) top coat. Many bond coats are comprised of a $\beta$-NiAl intermetallic compound that serves as an aluminum reservoir to maintain a protective $\alpha$-alumina TGO. Currently, bond coatings are often not designed with thermo-mechanical properties in mind, yet as they represent a significant fraction of the airfoil cross section, their role in damage accumulation is likely important [2].

Several intrinsic failure mechanisms of coatings such as rumpling, edge delamination, and cracking due to thermo-mechanical fatigue (TMF), limit the lifetimes of engine blades [3-5]. Sustained peak low-cycle fatigue (SPLCF) cracks have become a more significant problem as wall thicknesses decrease, and higher thermal gradients occur through the airfoil wall [6]. Such thermal gradients place the surface of the airfoil in a state of compression, where at operating temperatures the material creeps to relax the stresses. When the load is released at the end of the engine cycle, a residual tensile stress remains as the cool back side of the airfoil geometrically constrains the material at the surface. This cycling continues,

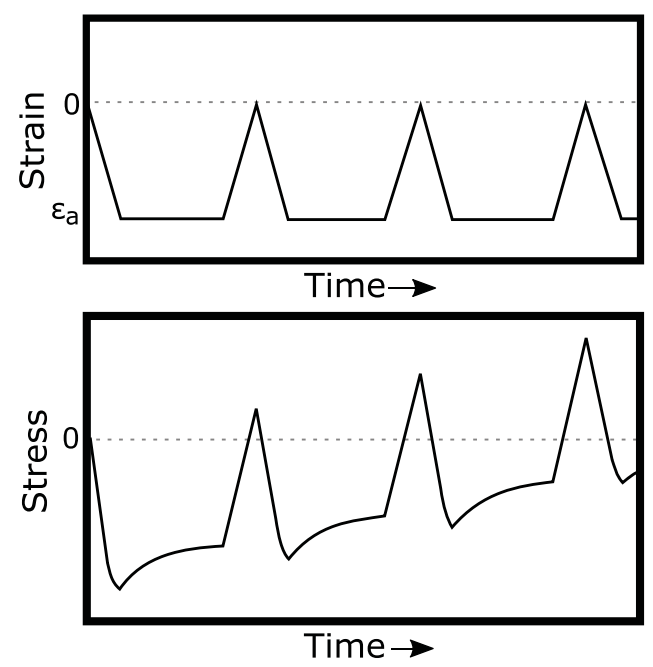

Figure 1. Schematic of the (top) applied strain cycles and the (bottom) resulting stress response. The applied compressive strain in this work was $\varepsilon_{a}=0.35 \%$ at $1093{ }^{\circ} \mathrm{C}$.

leading to an oxide-assisted crack initiation and growth process. Previous research has demonstrated that coatings influence the lifetime under SPLCF cycling conditions $[2,7]$.

Evans et al. have proposed a mechanism for the propagation of oxide-assisted fatigue cracks which has been used to develop finite element models that provide insight into important material parameters affecting crack growth rates $[2,9]$. The rate of degradation is sensitive to the mechanical properties of the substrate and coating as well as on the presence of growth strains in the oxides formed on the sample and crack surfaces. While the strengths of superalloy substrates are well known, the strength of various bond coat materials are relatively unknown and only a few studies report properties such as creep rate and the coefficient of thermal expansion (CTE) $[10,11]$. Both stronger single crystal substrates and bond coat materials are predicted to reduce crack propagation rates in SPLCF [2]. Additionally, growth strains that develop in the oxide scale as new $\mathrm{Al}_{2} \mathrm{O}_{3}$ is created along grain boundaries play an important role. The newly formed alumina is accommodated by in-plane straining of neighboring grains. Intermetallic coatings at temperatures around $1100{ }^{\circ} \mathrm{C}$, generally develop alumina scales with compressive growth stresses on the order of $200-300 \mathrm{MPa}$, where the magnitude of the stress is a balance between the lateral straining due to continued oxide growth, and creep relaxation of the neighboring grains $[9,12,13]$. Growth of short cracks is believed to be enhanced significantly by the presence 
Table I. Composition (wt.\%) of the single crystal superalloys and the EQ bond coat (TMBC-1) [8].

\begin{tabular}{lccccccccccc}
\hline & $\mathrm{Ta}$ & $\mathrm{Al}$ & $\mathrm{Cr}$ & $\mathrm{Co}$ & $\mathrm{Mo}$ & $\mathrm{W}$ & $\mathrm{Re}$ & $\mathrm{Ru}$ & $\mathrm{Hf}$ & $\mathrm{Y}$ & $\mathrm{Ni}$ \\
\cline { 2 - 10 } René N5 & 6.5 & 6.2 & 7.0 & 7.5 & 1.5 & 5.0 & 3.0 & - & 0.15 & - & bal. \\
TMS-138A & 5.6 & 5.7 & 3.2 & 5.8 & 2.8 & 5.6 & 5.8 & 3.6 & 0.1 & - & bal. \\
EQ Coating & 9.9 & 8.1 & 4.0 & 6.2 & 1.0 & 4.5 & - & - & 0.4 & 0.1 & bal. \\
\hline
\end{tabular}

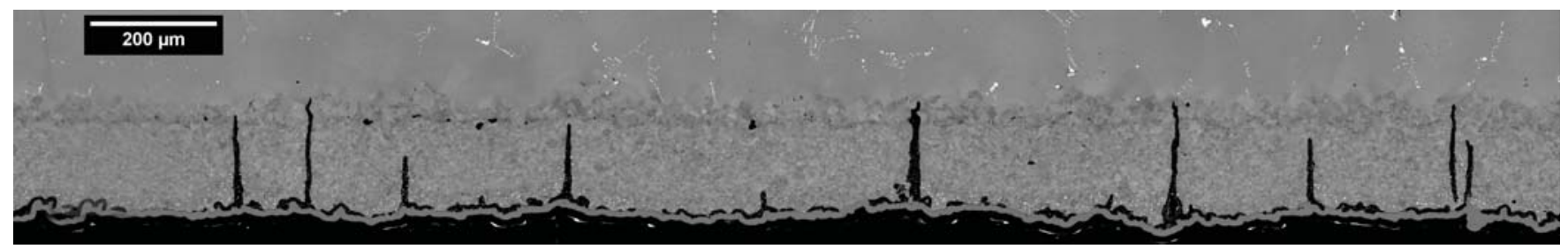

(a)

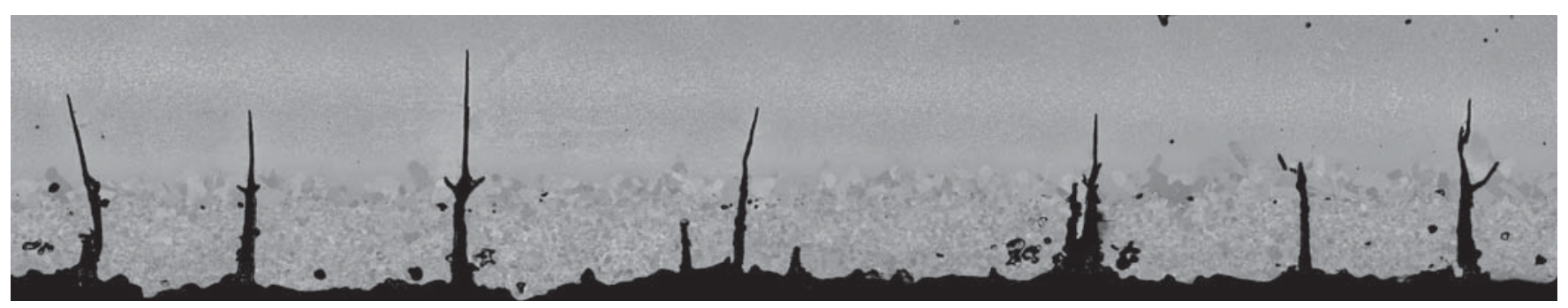

(b)

Figure 2. BSE images of longitudinal sections of (a) René N5 and (b) TMS-138A with EQ bond coats tested to failure (6134 and 19142 cycles, respectively). The final collodial silica polish provided for grain contrast in the coating. Note that the René N5 specimen was electroplated with $\mathrm{Ni}$ to retain the surface oxides and that the image contrast is such that the oxide filling the cracks appears black.

of these growth strains [2,9]. In this case, crack growth can occur both upon unloading where a tensile stress is observed and at the maximum compressive load where the TGO is elongated and driven into the underlying coating or substrate material $[2,7,9]$.

Current bond coatings used in industry include platinum aluminides and MCrAlYs. Both of these materials are susceptible to rumpling, which is indicative of low coating creep strength at elevated temperatures [14-17]. To minimize interdiffusion zones and to create stronger bond coatings new classes of single phase $\gamma^{\prime}$ or two-phase $\gamma-\gamma^{\prime}$ have recently been investigated $[8,18]$. Kawagishi et al., developed near- $\gamma^{\prime}$ coatings designed to be in equilibrium with the substrate material [8]. The present research focuses on a particular equilibrium (EQ) coating, TMBC-1, designed to be similar to the $\gamma^{\prime}$ phase of René N5 [8]. In addition to being composed of more creep resistant phases, these coatings show reduced interdiffusion zones (IDZs) when deposited on typical superalloy substrates. For example, while TMBC-1 is not an EQ coating designed for TMS-138A, only a small diffusion zone and no secondary reaction zone (SRZ) is observed after 300 hours at $1100^{\circ} \mathrm{C}$. In stepped thermal cycling that causes a NiCoCrAlY bond coat to rumple, the EQ coating is resistant to rumpling [17]. Several factors in the study could have led to reduced rumpling, including a thicker EQ coating, reduced CTE mismatch between EQ coatings and base superalloys, and increased creep strengths of the near- $\gamma^{\prime}$ coating.
To date, uncoated René N5 and vapor phase aluminide coatings have been studied in sustained peak low-cycle fatigue [2,7]. The objective of this research is to examine whether a rumpling resistant $\gamma-\gamma^{\prime}$ EQ coating is better at mitigating damage due to SPLCF. Detailed microscopy including electron backscatter diffraction (EBSD) analysis provides insights into the crack propagation and damage occurring in the systems examined and their relationship to coating microstructure and TGO growth stresses.

\section{Experimental Procedure}

Cylindrical fatigue bars of 2nd and 4th generation single crystal Ni-base superalloys René N5 and TMS-138A, respectively, were machined for loading along the [001] direction. An EQ $\gamma-\gamma^{\prime}$ coating, TMBC-1, developed by NIMS in Japan was deposited on the two different alloys using vacuum plasma spray (VPS) (Table I) [8]. SPLCF tests were conducted isothermally in air at $1093{ }^{\circ} \mathrm{C}$ in strain control with $A=-1(R=-\infty)$, the SPLCF test waveform is shown in Figure 1. The specimens were loaded compressively to a strain of $-0.35 \%$, held for two minutes, then unloaded to zero strain and reloaded within 3 seconds. One specimen of each coating/superalloy combination was tested until failure, while the remaining samples were tested to varying degrees of their expected life. Failure was defined as either a $50 \%$ load drop from the maximum tensile load or fracture of the specimen depending on which occurred first. 


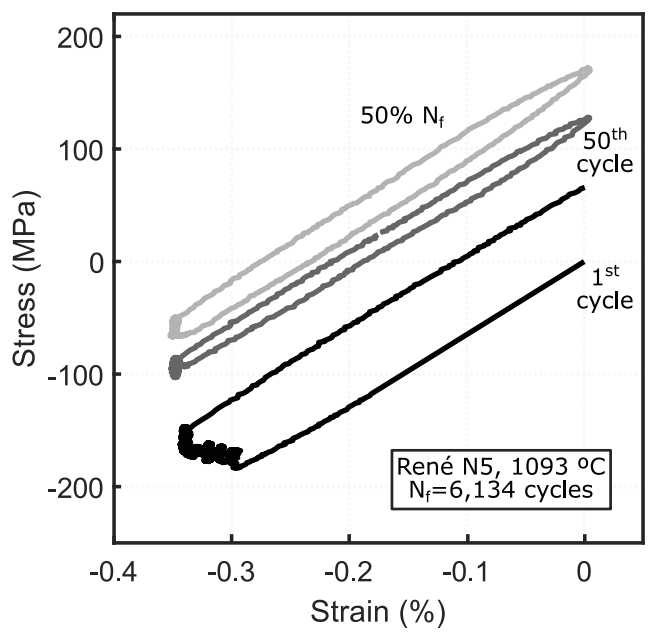

(a)

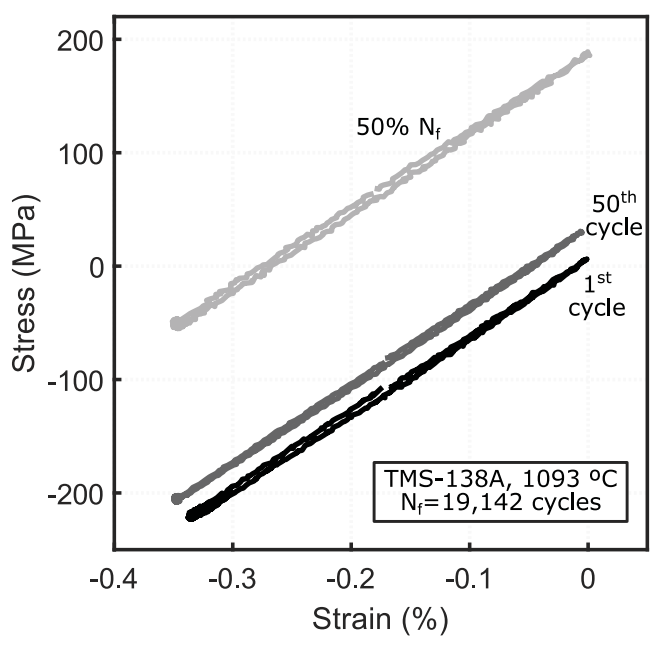

(b)

Figure 3. Stress-strain hysteresis loops for select cycles: 1, 50, and $50 \%$ of life for (a) René N5 and (b) TMS-138A.

After cycling, the fatigue specimens were sectioned longitudinally and metallographically prepared. Optical and scanning electron microscopy (SEM) was completed to examine microstructure, crack lengths, and oxide thickness. Electron backscatter diffraction (EBSD) was completed to determine the grain structure of the coatings. Samples for EBSD were prepared to a final collodial silica vibratory polishing step. Maps of various regions in both René N5 and TMS-138A specimens were collected from the surface of the fatigue specimen through the coating and into the single crystal superalloy. EBSD combined with energy dispersive spectroscopy (EDS) was collected at select regions around cracks within the coating. EBSD data were acquired with a sample tilt of $70^{\circ}$, a working distance of 13-17 $\mathrm{mm}$ and a step size of $0.2-0.3 \mu \mathrm{m}$ at an operating voltage of $20 \mathrm{kV}$. A grain tolerance angle of $5^{\circ}$ was used to partition the data. All inverse pole figure (IPF) maps shown are in reference to the loading direction of the specimen. Grain reference orientation deviation (GROD) maps were produced to investigate the presence of damage in the coating/substrate system. The GROD for each grain is defined as the misorientation angle between each pixel in a grain and the average orientation for the grain. Electron-probe microanalysis (EPMA) line scans through the coating and into the superalloy were performed to gain insight on the extent of the interdiffusion and to assess the role of coating microstructure. Specimens for EPMA were polished flat to a finish of $0.25 \mu \mathrm{m}$. A René N5 standard of known composition was solution heat treated and quenched for use as a standard. Several areas of the standard were analyzed to calibrate the system.

\section{Results}

Figure 2 shows backscattered electron (BSE) images of longitudinal sections of each alloy cycled to failure. The lifetimes and crack depths of the EQ coated specimens are reported in Table II. The lifetimes of the EQ coated René N5 and TMS-138A vary significantly due to the difference in substrate creep strength, with TMS-138A exhibiting a fatigue life about three times longer than René N5. EQ coated René N5 has a 10\% reduction in fatigue life as compared to uncoated René N5 [2].

\section{$\underline{\text { Stress-Strain Hysteresis Response }}$}

Figure 3 shows stress-strain hysteresis loops of select cycles throughout the SPLCF test. Due to the creep relaxation during the hold period, a residual tensile stress develops at the end of the first cycle (upon returning to zero strain). With subsequent cycling, the hysteresis loops shift upward to higher tensile stresses. The loops reach a steady state by approximately 1000 and 5000 cycles (16 to 26 percent of the total life) for René N5 and TMS-138A, respectively. Only minor upward shifts occur with each additional cycle beyond this point, where the maximum tensile stress observed at zero strain attains a constant value of $170 \mathrm{MPa}$ and $190 \mathrm{MPa}$ for René N5 and TMS-138A. During the two minute hold of the first cycle, René N5 experiences a stress relaxation of 65-70 $\mathrm{MPa}$ that rapidly reduces to $10-15 \mathrm{MPa}$ in the following cycles. The more highly alloyed TMS-138A creep relaxes considerably less than René N5 during the compressive hold and does not show a significant stress relaxation difference between the first and subsequent cycles. TMS-138A specimens show a reduction in stress of 8-10 MPa between the start and end of each two minute hold at the maximum compressive strain.

\section{Microstructure}

The grain size and overall coating structure does not vary between the two substrate superalloys and the following observations pertain to both alloys. The EQ $\gamma-\gamma^{\prime}$ coating was deposited to be approximately 140-150 $\mu \mathrm{m}$ thick and is comprised of small randomly oriented grains with an approximate grain size of 3-5 $\mu m$ (Figures 4 and 5). The grain size of the EQ coating does not appear to change significantly with increasing time at temperature, indicating no noticeable grain growth is occurring within the range of expected lifetimes tested. Phase contrast in backscatter electron images, as well as etching of the $\gamma^{\prime}$ phase, reveals the coating of a coarse $\gamma-\gamma^{\prime}$ phase structure (Figure 6). Furthermore, combined EDS/EBSD indicates that the $\gamma-\gamma^{\prime}$ phase boundaries do not coincide with the grain boundaries in the coating (Figures 4 and 7).

As expected for an EQ coating, the development of a typical interdiffusion zone (IDZ) often observed in $\beta$-phase coatings 
Table II. Summary of crack measurements for the two single crystal superalloys with an EQ bond coat.

\begin{tabular}{|c|c|c|c|c|c|c|c|c|}
\hline \multirow[b]{2}{*}{$\begin{array}{l}\text { Fraction } \\
\text { of Life }\end{array}$} & \multicolumn{4}{|c|}{ René N5 } & \multicolumn{4}{|c|}{ TMS-138A } \\
\hline & Cycle & $\begin{array}{l}\text { Avg. Depth } \\
(\mu m)\end{array}$ & $\begin{array}{l}\text { Max Depth } \\
\quad(\mu m)\end{array}$ & $\begin{array}{l}\text { Spacing } \\
(\mu m)\end{array}$ & Cycle & $\begin{array}{l}\text { Avg. Depth } \\
(\mu m)\end{array}$ & $\begin{array}{l}\text { Max Depth } \\
\quad(\mu m)\end{array}$ & $\begin{array}{l}\text { Spacing } \\
(\mu m)\end{array}$ \\
\hline $50 \%$ & 3069 & 53 & 164 & 230 & 9684 & 141 & 352 & 215 \\
\hline $75 \%$ & 4515 & 68 & 2350 & 143 & 14439 & 202 & 898 & 194 \\
\hline $100 \%$ & 6134 & 98 & 3725 & 192 & 19142 & 167 & 3314 & 210 \\
\hline
\end{tabular}
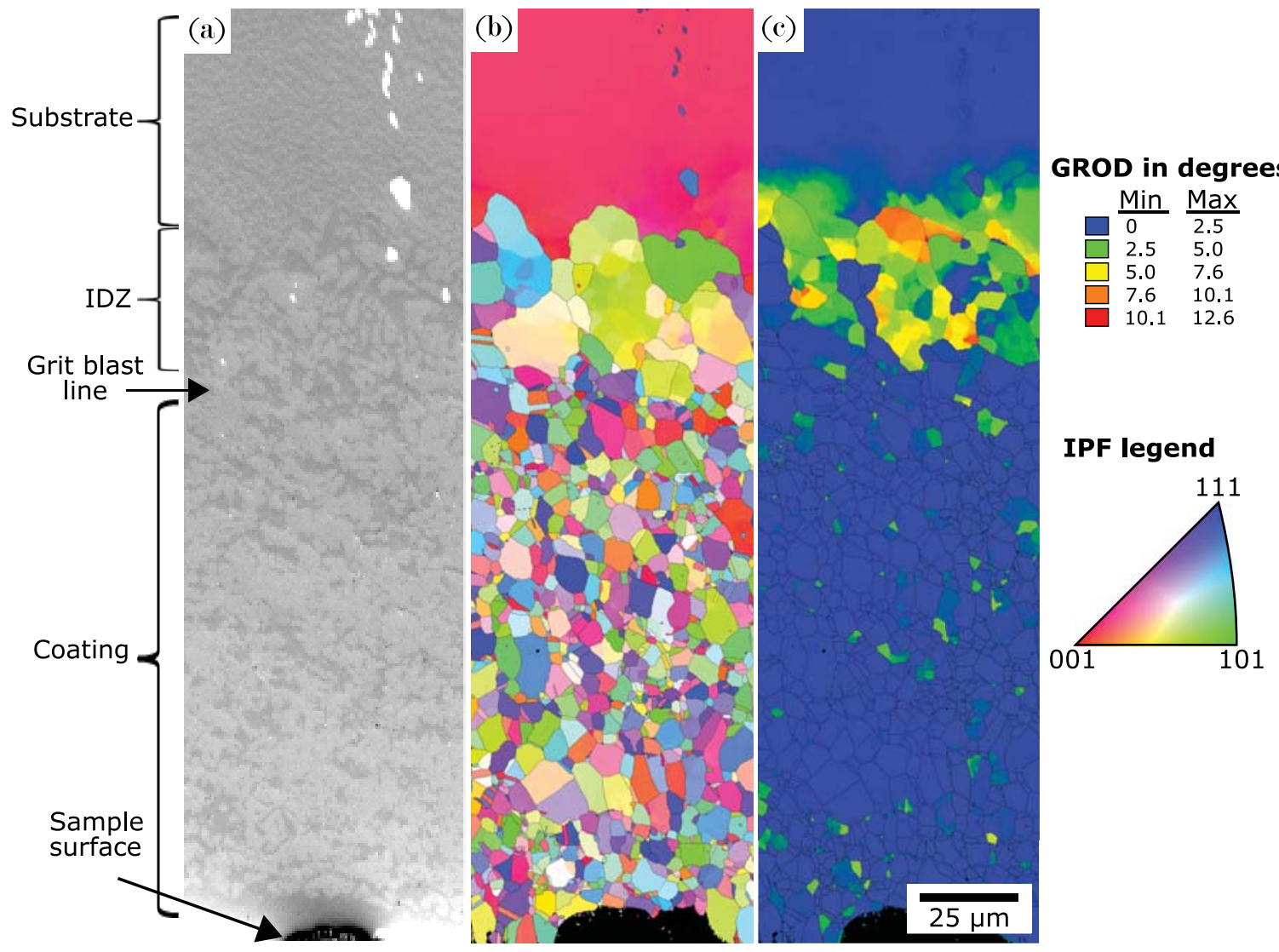

Figure 4. Electron backscatter diffraction of the EQ coating on René N5, BSE image showing $\gamma-\gamma^{\prime}$ phase contrast (a), inverse pole figure map showing the grain structure and orientation (b) and grain reference orientation deviation (GROD) map showing significant misorientations indicative of a high dislocation content near the IDZ (c). This specimen was tested to $75 \%$ life, however, the coating microstructure is similar for all cycling times examined.

is suppressed, and precipitation of refractory-rich phases is not observed. However, an interdiffusion zone is still observed in a 40-50 $\mu \mathrm{m}$ region below the grit blast line for both substrate alloys. The general location of the grit blast line was determined from the location of residual alumina particles that are observable in scanning electron micrographs. This region is characterized by a larger grain size, the development of subgrains, cellular reprecipitation of $\gamma^{\prime}$, and misorientations indicative of a high dislocation content in the single crystal substrate at the coating/substrate interface (Figure 4). More detailed analysis of the grain sizes indicates a transition from average grain sizes of $4 \mu \mathrm{m}$ to larger grain sizes averaging $7 \mu m$ in diameter, with some grains as large as 20-35 $\mu \mathrm{m}$. GROD maps (Figure 4) show the increase in overall misorientation within the grains in the original single crystal substrate below the grit blast.

To further examine the extent of interdiffusion, as well as the properties of the coating/substrate interface, EPMA line scans of René N5 specimens were completed, Figure 8. The compositional analysis was split into regions where the electron beam sampled primarily the $\gamma$ phase, and primarily the $\gamma^{\prime}$ phase. As observed by backscatter electron images, an $\mathrm{Al}$ depleted layer of $\gamma$ persists through the first $20 \mu \mathrm{m}$ of the coating due to depletion of aluminum during oxidation. Table III summarizes the average compositions of the various regions of the coating/substrate system. Overall, the aluminum concentration remains relatively constant through 
Table III. Average composition (wt.\%) of the $\gamma$ surface layer, coating, interdiffusion zone (IDZ), and substrate as shown in Figure 8 .

\begin{tabular}{lcccccccccc}
\hline & $\mathrm{Ta}$ & $\mathrm{Al}$ & $\mathrm{Cr}$ & $\mathrm{Co}$ & $\mathrm{Mo}$ & $\mathrm{W}$ & $\mathrm{Re}$ & $\mathrm{Hf}$ & $\mathrm{Y}$ & $\mathrm{Ni}$ \\
\cline { 2 - 10 } Surface Layer & 5.3 & 3.1 & 9.1 & 10.7 & 1.8 & 6.6 & 0.3 & 0.3 & 0.1 & 62.8 \\
Coating & 9.7 & 5.9 & 4.6 & 7.4 & 1.0 & 5.0 & 0.3 & 0.2 & 0.1 & 66.0 \\
IDZ & 6.2 & 5.1 & 7.0 & 9.1 & 1.3 & 5.3 & 1.3 & - & - & 64.7 \\
Substrate & 6.3 & 6.1 & 6.5 & 7.3 & 1.3 & 4.8 & 2.7 & 0.1 & - & 64.8 \\
\hline
\end{tabular}

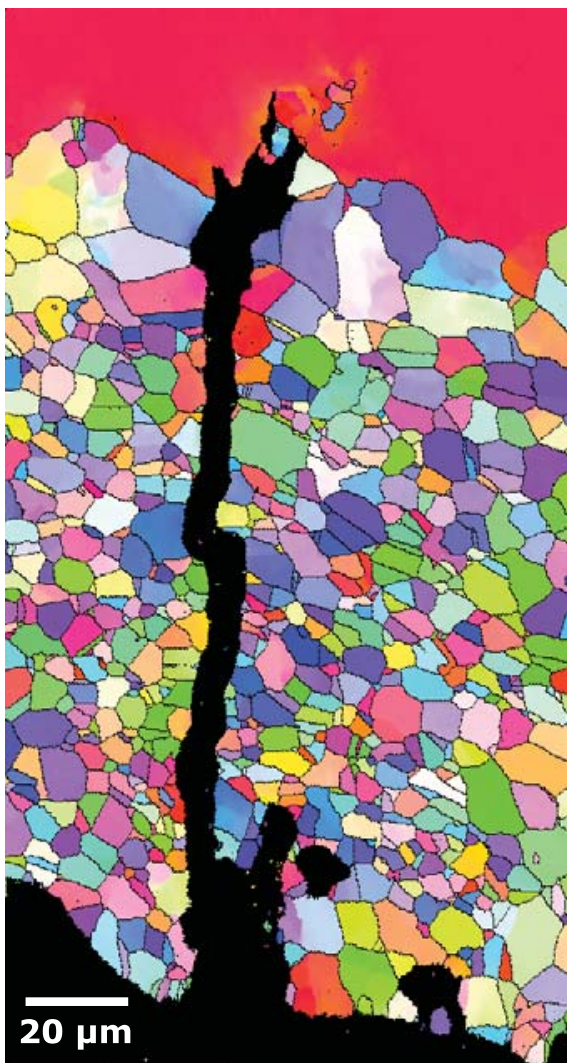

Figure 5. Inverse pole figure map of a crack penetrating the EQ bond coat on TMS-138A after being interrupted at $50 \%$ of the expected life. The orientation reference direction is the same as the loading direction.

the coating and into the superalloy. The aluminum concentration measured in the EQ coating is approximately $2 \mathrm{wt} . \%$ lower than the nominal composition. However, as-deposited material of the EQ coating has not been characterized in terms of composition (in this work or prior work), it is unclear as to what extent of the aluminum depletion is due to oxidation and interdiffusion during the SPLCF testing. Spray processes are susceptible to particle oxidation during coating formation and small particles less than $0.5 \mu \mathrm{m}$ in size are observed in the coating (Figure 9). Furthermore, small bright particles are observed within the coating. A steady increase of rhenium in the $\gamma$ phase is observed as a function of depth through the coating and into the superalloy, as René N5 contains 3 wt.\% Re and no Re is added to the coating. This indicates interdiffusion is occurring throughout the test while at elevated temperatures. Similarly, a gradient in Ta is observed, as the coating has about

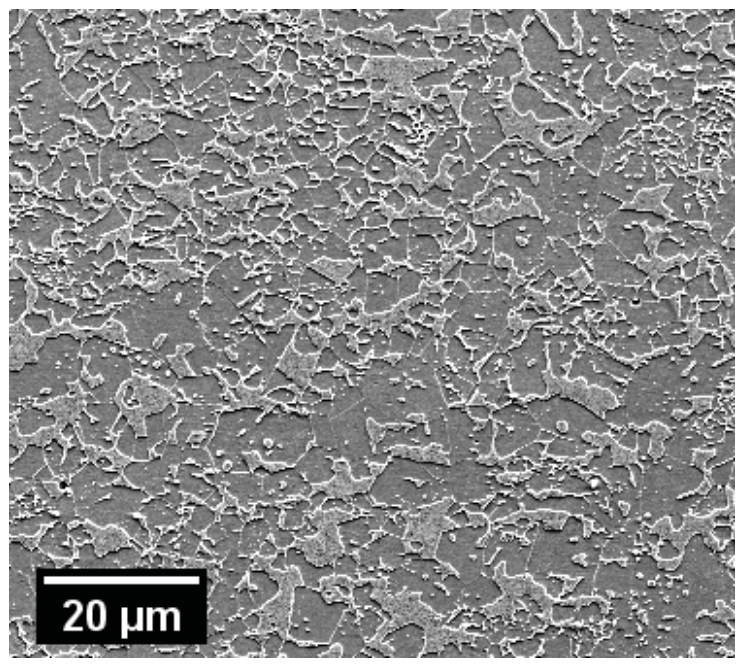

Figure 6. Secondary electron image of the EQ coating on a René N5 specimen. The $\gamma^{\prime}$ has been preferentially etched such that the dark regions are $\gamma^{\prime}$ and the light regions are $\gamma$.

3\% more Ta than René N5. Although EPMA line scans were not completed on TMS-138A, significant gradients in $\mathrm{Re}$ and $\mathrm{Ru}$ are expected through the coating/substrate.

\section{Crack Propagation}

By $50 \%$ life and beyond, the crack spacing in all EQ coated specimens is constant, at approximately $200 \mu \mathrm{m}$, indicating that crack initiation has slowed or ceased, and existing cracks are increasing in length (Table II). The average crack lengths in the TMS-138A samples are approximately twice that of the René N5 at comparable fractions of life (yet a different number of cycles). Propagation of all the cracks in the TMS-138A specimens occurs for a longer period before critical crack growth dominates, indicating that critical cracks leading to final failure of the sample occur sooner with the weaker substrate alloy.

After cycling, cracks in the coating are intergranular, and the crack faces have oxidized to form a layer of $\alpha$-alumina (Figures 5 and 7). Additionally, as the crack faces oxidize, a depleted layer of $\gamma$ develops around the crack. TMS-138A samples were tested over 400 hours longer than the René N5 specimens and have larger depleted regions at the surface and around crack faces. The softer $\gamma$ layer weakens the material around the cracks and finite element modeling indicates this enhances crack propagation rates [2]. Furthermore, even in the higher strength TMS-138A, deformation in front of the crack tip is significant enough to cause 

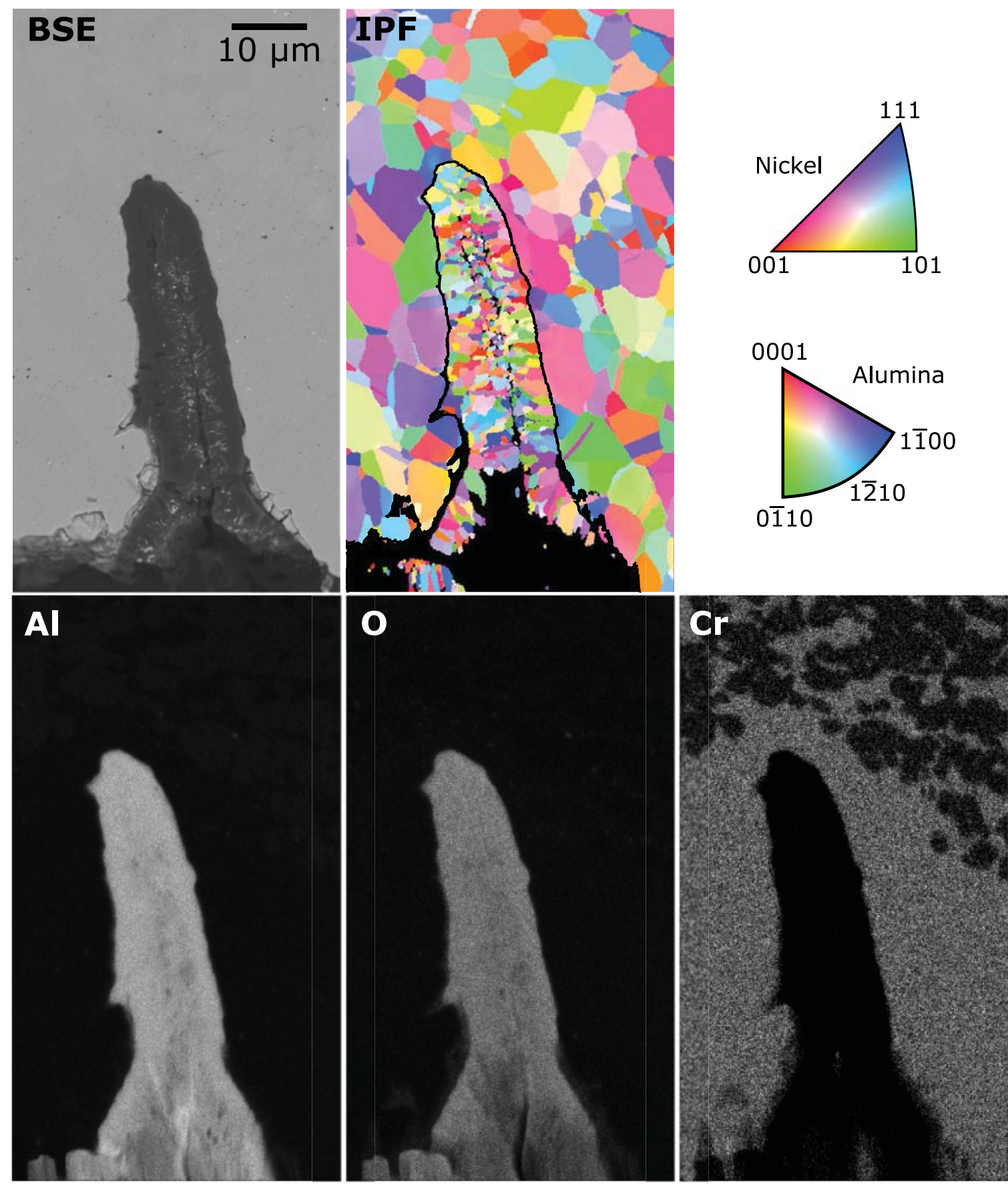

Figure 7. EBSD orientation map and corresponding EDS maps of a crack contained within the coating on TMS-138A tested to $75 \% \mathrm{~N}_{f}$ $(14,439$ cycles $)$. The boundary between the oxide and coating grains is outlined in black on the IPF map. 


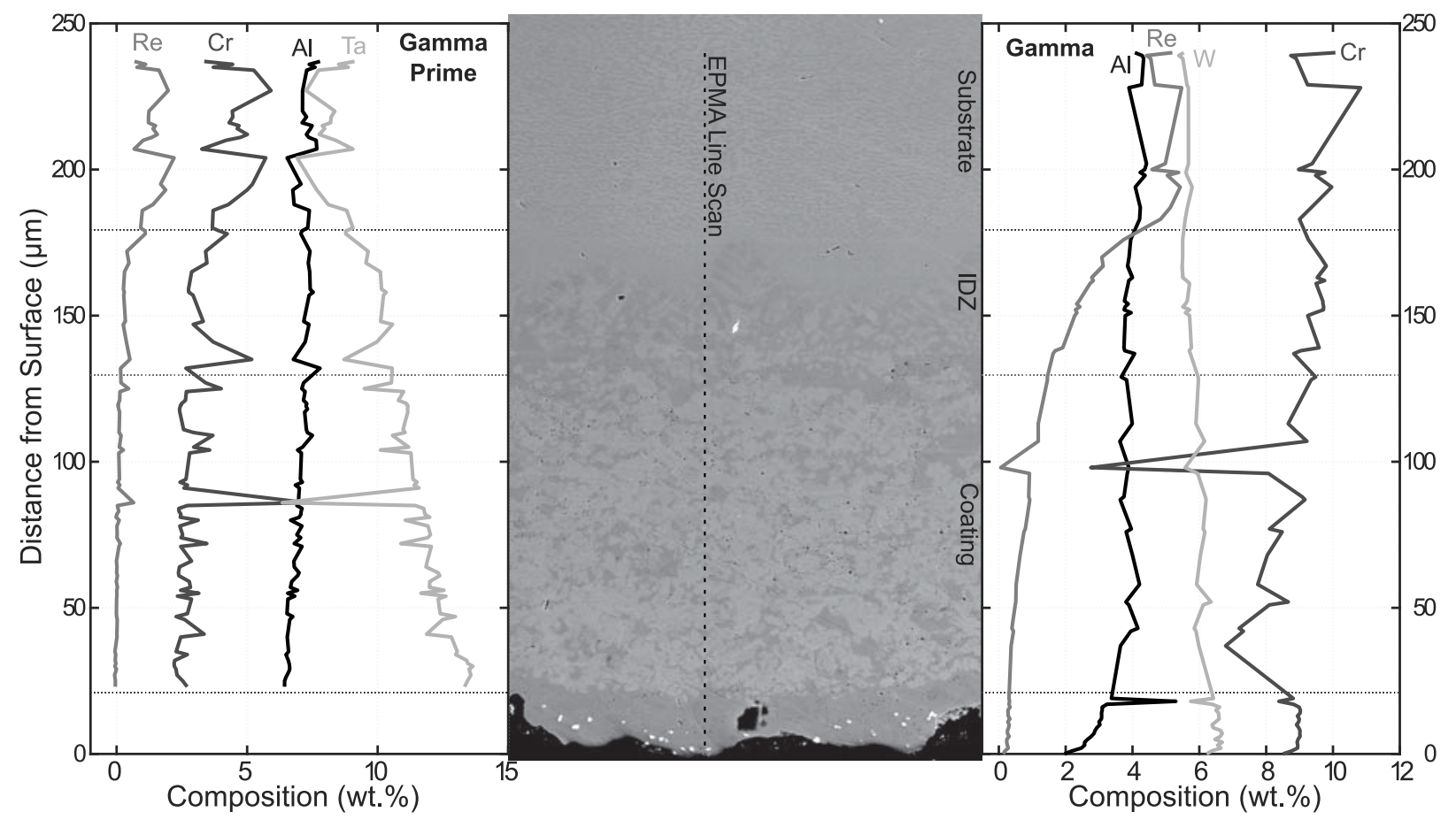

Figure 8. Compositions in the $\gamma^{\prime}$ (left) and $\gamma$ (right) phases as determined from an EPMA line scan through the EQ coating on René N5 for a specimen tested to $75 \%$ of the expected life. Select elements are shown here, and average compositions in each region are listed in Table III.

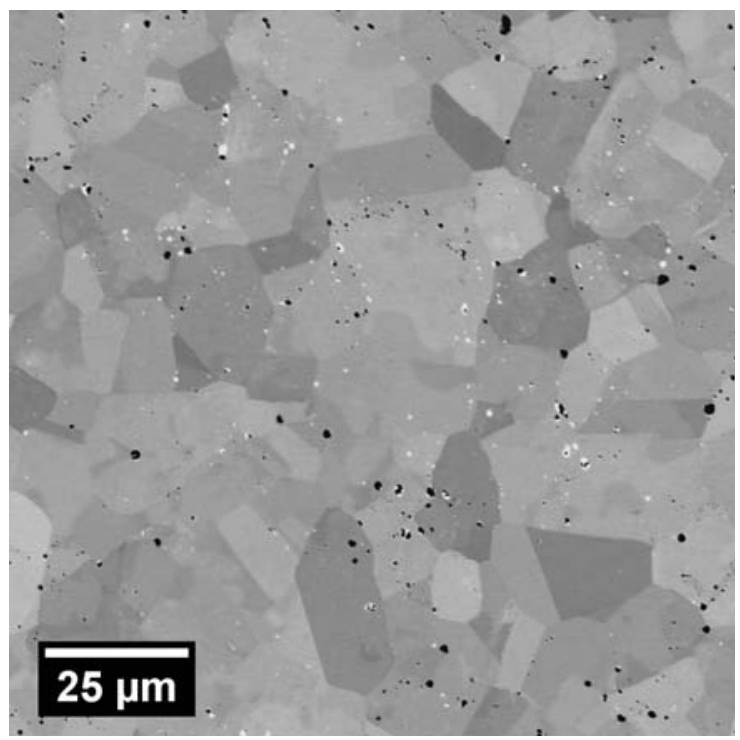

Figure 9. BSE image within the EQ coating on a TMS-138A specimen tested to failure showing the existence of small oxides (dark) and bright precipitates. Grain contrast is observed from a final collodial silica polish.

occasional recrystallization in the single crystal substrate (Figure 5). Figure 10 shows cracks penetrating just beyond the IDZ in both substrate alloys. A tendency of cracks to bend or branch to follow the large grains in the IDZ is observed.

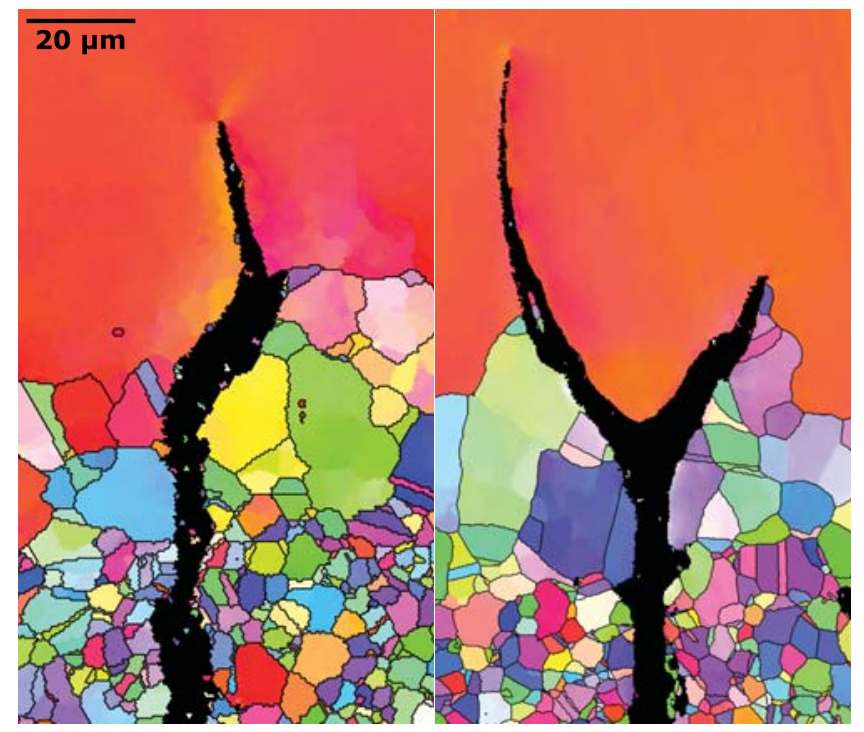

Figure 10. Inverse pole figure maps of cracks penetrating through the interdiffusion zone in René N5 (left) and TMS-138A (right).

\section{Discussion}

Failure during SPLCF cycling is a complex process that is influenced by many competing factors. In this work, dramatically different creep strengths of the substrate alloys (René N5 and TMS-138A) dominate the crack propagation rates and total cycles to failure. An increase in cycles to failure from 6134 for René N5 
to 19142 for TMS-138A occurs. At 50\% life, the longest observed crack in EQ coated René N5 is just about to penetrate the substrate, whereas in TMS-138A specimens, cracks have already penetrated into the single crystal. The significant difference in creep between the 2nd generation René N5 and 4th generation TMS-138A likely outweighs any differences in oxidation properties and growth strains in the developing TGO. Furthermore, the enhanced substrate strength of TMS-138A decreases the crack propagation rates once crack tips reach the interface between the bond coat and single crystal. With slower crack propagation rates in the single crystal and an overall longer lifetime, the crack faces are more oxidized and appear more open in Figure 2.

The development of larger grains, increased grain orientation spread, and misorientations in the single crystal substrate at the coating, Figures 4 and 10, interface indicates a grain growth/recrystallization process is operative. The existence grains that possess varying levels of misorientation (deformation) and with varying degrees of subgrain formation indicates that dynamic recrystallization is likely ongoing throughout the test.

EPMA results suggest interdiffusion and compositional variations may play a role in deformation and crack propagation in the IDZ. The precipitous drop off of Re in the $\gamma$-phase (Figure 8) will lead to a quick reduction in creep resistance in the single crystal near the interface and through the IDZ. The formation of new and/or larger grains in this region allow for additional "easy" crack growth along grain boundaries before propagating into the single crystal superalloy. BSE images as well as EBSD maps show many of the bifurcated cracks follow grain boundaries between the single crystal and coating. Crack bifurcation is more common in the stronger TMS-138A alloy (Figures 2 and 10). SEM micrographs indicate a more significant IDZ on the TMS-138A samples, however discerning whether the interdiffusion is more significant due to differences in thermodynamic activity between the coating and substrate or simply due to increased time at temperature is out of the reach of the current study.

EQ coatings were subjected to SPLCF cycling to elucidate the effect of stronger (higher yield strength, more creep resistant) bond coatings on crack propagation. However, the EQ coated René N5 sample under performs by 2000, and 4000 cycles compared to uncoated René N5 and vapor phase aluminide (VPA) coated René N5, respectively [2,7]. A few distinct differences exist between the EQ coatings and VPA coatings. First, the VPA coatings begin as $\beta$ and transition to $\gamma^{\prime}$ as $\mathrm{Al}$ is depleted due to oxidation and interdiffusion. This phase transition to a more creep resistant phase may slow crack propagation as cracks that are known to initiate in the $\beta$ layer eventually encounter a $\gamma^{\prime}$ interface before exiting the bond coat [7]. Next, the VPA specimens have a coating thickness on the order of $50 \mu \mathrm{m}$ with significantly larger grains [7]. Finite element modeling of the substrate/coating system indicates that a decrease in thickness of weaker coatings can lead to comparable crack lengths to a thicker coating with twice the high temperature yield strength [19]. The difference in both expected coating strength and coating thickness makes comparison between previous SPLCF studies of René N5 with $\beta$-phase coatings more difficult.

The effect of oxide growth stresses on the EQ coatings can be compared to VPA coated materials and bare René N5 based on prior work $[13,17,20]$. Room temperature growth stresses in alumina scales formed on uncoated René N5 after isothermal oxidation at $1093{ }^{\circ} \mathrm{C}$ are reported to range from -3.7 to $-4.0 \mathrm{GPa}$. This equates to growth strains at temperature of $0.21 \%$ [13]. Interrupted samples of EQ coated material during stepped thermal cycling have an average oxide stress of $-3.5 \mathrm{GPa}$ [17]. As the EQ coating was designed to be similar to René N5, similar growth stresses, as well as CTE values, are expected. The room temperature growth stress on VPA material was measured as $-2.7 \mathrm{GPa}$, and strains of $-0.09 \%$ were measured in-situ at $1093{ }^{\circ} \mathrm{C}$ [20]. While the CTE of EQ coatings may be more similar to the substrate material than a $\beta$-phase coating, VPA materials have both lower room temperature and high temperature oxide stresses than René N5. Finite element modeling in prior work predicts the lower TGO stresses in the VPA coating may be enhancing its resistance to crack propagation.

While finite element modeling can provide useful insights into the desirable properties for coatings that are more resistant to rumpling and thermo-mechanical fatigue, current models do not include the effects that microstructure plays in both creep and fatigue. The microstructure of the EQ coating provides several plausible explanations for the degradation in SPLCF life of the René N5 specimens compared to uncoated René N5. The smaller grains present in the coating create a high density of grain boundaries. Grain boundaries can serve as sites for crack initiation, provide a path for crack propagation, and supply fast diffusion paths for enhanced creep rates. The coarse $\gamma-\gamma^{\prime}$ phase distribution in the alloy also diminishes the creep properties of the coating compared to the fine and well ordered $\gamma-\gamma^{\prime}$ structure expected of bulk superalloys. Observations from this study as well as prior studies indicate that many aspects of coatings need to be considered in future studies to best optimize coating properties in order to mitigate damage due to oxide-assisted fatigue cracks. Properties such as coating strength, thickness and microstructure will strongly influence life and merit further systematic studies.

\section{Conclusions}

1. Coatings deposited on TMS-138A exhibited longer fatigue lives due to the enhanced base alloy properties.

2. While the EQ coating, TMBC-1, is resistant to rumpling, it does not increase resistance to oxide-assisted crack growth as compared to $\beta$ aluminide coatings deposited on René N5.

3. Crack growth dominates over crack initiation beyond $50 \%$ of the expected life in sustained peak low-cycle fatigue for both substrate materials.

4. The microstructural properties likely offset the benefits of a two phase $\gamma-\gamma^{\prime}$ coating. The coarse phase distribution, and small grain size diminish improvements in creep strength that EQ coatings may have over $\beta$-phase coatings.

\section{Acknowledgments}

The authors are grateful for the support of ONR Grant Number N00014-14-1-0618 and GE Global Research (A. Suzuki). 


\section{References}

1. D.R. Clarke and C.G. Levi, "Materials Design for the Next Generation Thermal Barrier Coatings," Annual Review of Materials Research, 33 (1) (2003), 383-417.

2. T.M. Pollock et al., "Oxide-Assisted Degradation of Ni-Base Single Crystals During Cyclic Loading: the Role of Coatings," J. Am. Ceram. Soc., 94 (2011), s136-s145.

3. C.G. Levi et al., "Environmental Degradation of Thermal-Barrier Coatings by Molten Deposits," MRS Bull., 37 (10) (2012), 932-941.

4. W.J. Zhang, "Thermal Mechanical Fatigue of Single Crystal Superalloys: Achievements and Challenges," Mater. Sci. Eng. A, 650 (2016), 389-395.

5. J.J. Moverare et al., "Thermomechanical Fatigue of Single-Crystal Superalloys: Influence of Composition and Microstructure" (Proceedings of the International Symposium on Superalloys, 2012), 369-377.

6. Y. Le Bihan, P.Y. Joubert, and D. Placko, "Wall Thickness Evaluation of Single-Crystal Hollow Blades by Eddy Current Sensor," NDT E Int., 34 (5) (2001), 363-368.

7. A. Suzuki et al., "Crack Progression During Sustained-Peak Low-Cycle Fatigue in Single-Crystal Ni-Base Superalloy René N5," Metall. Mater. Trans. A, 41 (4) (2010), 947-956.

8. K. Kawagishi et al., "EQ Coating: A New Concept for SRZ-Free Coating Systems" (Proceedings of the International Symposium on Superalloys, 2008), 761-768.

9. A.G. Evans et al., "A Mechanism Governing Oxidation-Assisted Low-Cycle Fatigue of Superalloys," Acta Mater., 57 (10) (2009), 2969-2983.

10. D. Pan et al., "Evolution of a Diffusion Aluminide Bond Coat for Thermal Barrier Coatings During Thermal Cycling," Acta Mater., 51 (8) (2003), 2205-2217.

11. W.J. Brindley and J.D. Whittenberger, "Stress Relaxation of Low Pressure Plasma-Sprayed NiCrAlY Alloys," Mater. Sci. Eng. A, 163 (1) (1993), 33-41.

12. D. Hovis et al., "In-Situ Studies of the TGO Growth Stresses and the Martensitic Transformation in the B2 Phase in Commercial Pt-Modified Nial and Nicocraly Bond Coat Alloys," International Journal of Materials Research, 98 (12) (2007), 1209-1213.

13. L.H. Rettberg et al., "Growth Stresses in Thermally Grown Oxides on Nickel-Based Single-Crystal Alloys," Metallurgical and Materials Transactions A, 47 (3) (2015), 1132-1142.

14. A.M. Karlsson, J.W. Hutchinson, and A.G. Evans, "The Displacement of the Thermally Grown Oxide in Thermal Barrier Systems Upon Temperature Cycling," Mater. Sci. Eng. A, 351 (1-2) (2003), 244-257.

15. D.R. Mumm, A.G. Evans, and I.T. Spitsberg, "Characterization of a Cyclic Displacement Instability for a Thermally Grown Oxide in a Thermal Barrier System," Acta Mater, 49 (12) (2001), 2329-2340.
16. C. Mercer et al., "Influence of Thermal Cycle on Surface Evolution and Oxide Formation in a Superalloy System With a NiCoCrAlY Bond Coat," Surf. Coatings Technol., 202 (20) (2008), 4915-4921.

17. C. Mercer et al., "A Comparative Investigation of Oxide Formation on EQ (Equilibrium) and NiCoCrAlY Bond Coats Under Stepped Thermal Cycling," Surf. Coatings Technol., 205 (8-9) (2011), 3066-3072.

18. J. Haynes et al., "Comparison of the Oxidation Behavior of $\beta$ and $\gamma-\gamma$ NiPtAl Coatings," Surf. Coatings Technol., 204 (6-7) (2009), 816-819.

19. M.A. Lafata et al., "Oxidation-Assisted Crack Growth Into Single Crystal Superalloy Substrates During Fatigue With Compressive Holds,", in preparation (2016).

20. A. Suzuki et al., "Oxide-Assisted Crack Growth in Hold-Time Low-Cycle-Fatigue of Single-Crystal Superalloys," MATEC Web Conf., 14 (2014), 04004. 